\title{
Controlling the Dynamics of Three Electron Spin Qubits in a Donor-Acceptor-Radical Molecule using Dielectric Environment
}

\author{
Haochuan Mao, Ryan M. Young, Matthew D. Krzyaniak, and Michael R. Wasielewski*
}

Department of Chemistry, Center for Molecular Quantum Transduction, and Institute for Sustainability and Energy at Northwestern, Northwestern University, Evanston, IL 60208-3113

*E-mail: m-wasielewski@,northwestern.edu

\section{Contents}

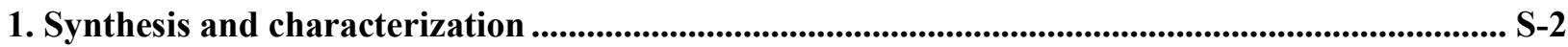

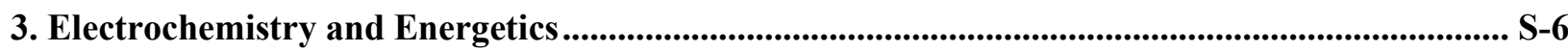

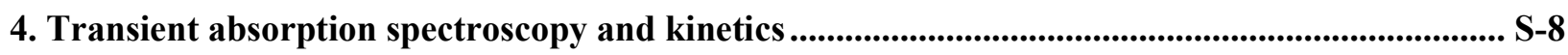

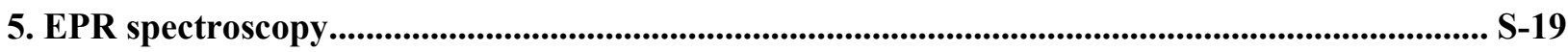

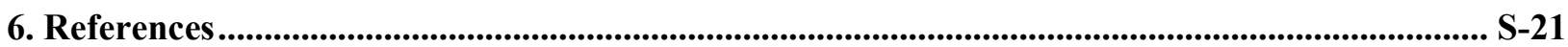




\section{Synthesis and characterization}

All chemicals were purchased from Sigma-Aldrich, Inc. unless noted otherwise. ${ }^{1} \mathrm{H}$ and ${ }^{13} \mathrm{C}$ NMR spectra were acquired with a Bruker Avance III $500 \mathrm{MHz}$ instrument equipped with a DCH CryoProbe. Mass spectroscopy was performed using a Bruker Autoflex III MALDI-TOF. Purification was performed using silica gel from Sorbent Technologies (Atlanta, GA). Scheme S1 outlines the syntheses of the compounds studied. The synthesis of $\mathbf{2}^{1}$ and $\mathbf{3}^{2}$ were described previously.

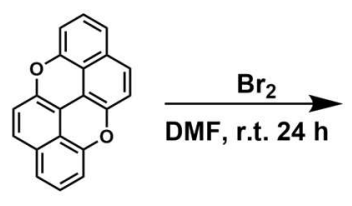

3

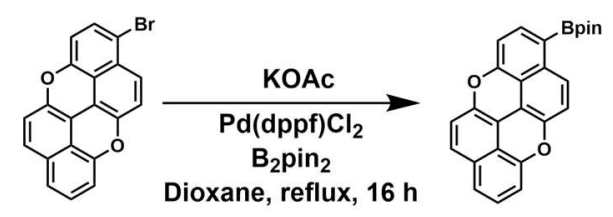

4

5
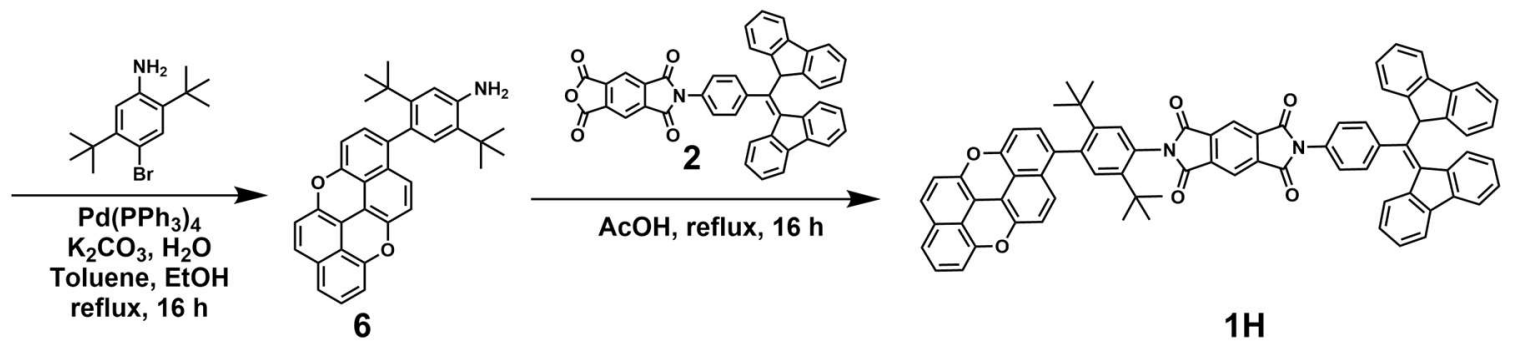

$1 \mathrm{H}$

Scheme. S1. Synthetic scheme for $\mathbf{1 H}$

Generation of $\mathbf{1}$ from its non-radical precursor $\mathbf{1 H}$ was performed immediately prior to experimentation using $\mathrm{MnO}_{2}$ and 1,5-diazabicyclo(4.3.0)non-5-ene in dry THF using methods previously described for the generation of $\mathrm{R}^{\bullet}$ derivatives. ${ }^{1}$ The resulting samples of $\mathbf{1}$ in THF were then evaporated to dryness using a stream of $\mathrm{N}_{2}$ before being dissolved in dry $\mathrm{CH}_{2} \mathrm{Cl}_{2}$, toluene, butyronitrile $(\operatorname{PrCN})$, or butyronitrile/propionitrile $(\operatorname{PrCN} / \mathrm{EtCN}, 9 / 2, \mathrm{v} / \mathrm{v})$ mixture for further study.

Compound 1H. A flame-dried round-bottom flask equipped with a magnetic stir bar was charged with $2(23.5 \mathrm{mg}, 37.1 \mu \mathrm{mol}, 1.2$ equiv.) and $\mathbf{6}(15.0 \mathrm{mg}, 30.9 \mu \mathrm{mol}, 1,0$ equiv. $)$, sealed with a rubber septum, and then subject to three pump-purge cycles with $\mathrm{N}_{2} .3 .5 \mathrm{ml}$ of degassed AcOH was added through the septum, and the mixture was hearted to reflux for $20 \mathrm{~h}$. The mixture was returned to 
room temperature and diluted with $20 \mathrm{ml}$ of $\mathrm{CH}_{2} \mathrm{Cl}_{2}$. After three extractions with $\mathrm{H}_{2} \mathrm{O}$, the organic layer was collected, and the solvent was removed on a rotary evaporator. The resulting crude mixture was then purified using chromatography on silica gel with $33 \%$ of hexane in $\mathrm{CH}_{2} \mathrm{Cl}_{2}$ as the eluent to yield $22.0 \mathrm{mg}(65 \%)$ of product as a dark green solid. ${ }^{1} \mathrm{H}$ NMR $(500 \mathrm{MHz}$, DMSO$\left.\mathrm{d}_{6}\right) \delta: 8.54(\mathrm{~d}, \mathrm{~J}=8.2 \mathrm{~Hz}, 1 \mathrm{H}), 8.42-8.38(\mathrm{~m}, 2 \mathrm{H}), 8.06(\mathrm{~d}, \mathrm{~J}=7.3 \mathrm{~Hz}, 1 \mathrm{H}), 7.94(\mathrm{~d}, \mathrm{~J}=7.7 \mathrm{~Hz}$ 1H), 7.88-7.83 (d, J = 7.4 Hz, 2H), $7.69(\mathrm{~s}, 1 \mathrm{H}), 7.68(\mathrm{~d}, \mathrm{~J}=7.6 \mathrm{~Hz}, 2 \mathrm{H}), 7.59-7.50(\mathrm{~m}, 2 \mathrm{H}), 7.47-$ $7.38(\mathrm{~m}, 3 \mathrm{H}), 7.35(\mathrm{td}, \mathrm{J}=7.4,1.0,2 \mathrm{H}), 7.32-7.27(\mathrm{~m} .2 \mathrm{H}), 7.27-7.23(\mathrm{~m}, 2 \mathrm{H}), 7.23-7.20(\mathrm{~m}, 1 \mathrm{H})$, $7.19(\mathrm{~d}, \mathrm{~J}=2.5 \mathrm{~Hz}, 1 \mathrm{H}), 7.17$ (d, J = 3.7 Hz), $7.15(\mathrm{~s}, 1 \mathrm{H}), 7.13$ (s, 2H), 1.19 (s, $9 \mathrm{H}), 1.10$ (s, 9H). ${ }^{13} \mathrm{C}$ NMR $\left(126 \mathrm{MHz}, \mathrm{CDCl}_{3}\right) \delta: 166.66,166.58,164.83,160.32,153.90,152.68,152.15,148.63$, $145.71,144.45,144.20,143.90,143.50,142.13,141.45,140.01,139.90,138.91,138.64,137.70$ $137,66,137.07,136.70,133.70,131.38,130.26,130.04,129.35,128.55,128.45,127.70,127.40$ $127.20,127.10,126.83,125.89,125.47,125.26,125.18,121.66,121.29,120.26,120.03,119.26$ 119.21, 117.46, 117.35, 111.49, 111.44, 108.71, 107.76, 36.16, 35.16, 31.97, 31.60. MS (MALDITOF) m/z: $\left[\mathrm{M}^{+}\right]$calculated for $\mathrm{C}_{77} \mathrm{H}_{52} \mathrm{~N}_{2} \mathrm{O}_{6} 1102.39$; found 1100.43 .

Compound 4. $300 \mathrm{mg}$ of $\mathbf{3}$ (1.06 mmol) and $190 \mathrm{mg}$ of $N$-bromosuccinimide (NBS) (1.06 mmol, 1 equiv.) were placed in a $250 \mathrm{ml}$ round-bottom flask equipped with a magnetic stir bar and sealed with a rubber septum. After three pump-purge cycles with $\mathrm{N}_{2}, 100 \mathrm{ml}$ of DMF was charged into the flask upon vigorous stirring at room temperature for $24 \mathrm{~h}$. The reaction suspension was then diluted with $\mathrm{H}_{2} \mathrm{O}$ and the solid was collected using vacuum filtration then washed with $20 \mathrm{ml}$ of methanol three times to remove unreacted NBS. The solid was dried in the air to yield $320 \mathrm{mg}$ of product as yellow solid, which was used for next step without further purification.

Compound 5. $500 \mathrm{mg}$ of 4 ( $0.69 \mathrm{mmol}), 700 \mathrm{mg}$ of bis(pinacolato)diboron (2.77 mmol, 4 equiv.), and $500 \mathrm{mg}$ of potassium acetate (5.54 mmol 8 equiv.) were combined in $50 \mathrm{~mL}$ of 1,4-dioxane. 
This mixture was purged with nitrogen for $15 \mathrm{~min}$. After adding $0.1 \mathrm{~g}$ of $\mathrm{Pd}(\mathrm{dppf}) \mathrm{Cl}_{2}(0.14 \mathrm{mmol})$, the mixture was purged with nitrogen for another $15 \mathrm{~min}$. The reaction mixture was then heated at $110{ }^{\circ} \mathrm{C}$ for $12 \mathrm{~h}$. After the reaction mixture was cooled, the solvent was removed on a rotary evaporator. The resulting mixture was purified by silica gel column chromatography with $\mathrm{CH}_{2} \mathrm{Cl}_{2} /$ hexanes/triethylamine (49/50/1) as the eluent yielding $0.4 \mathrm{~g}(71 \%)$ of yellow solid as the product. ${ }^{1} \mathrm{H}$ NMR $\left(500 \mathrm{MHz}, \mathrm{CDCl}_{3}\right), \delta: 8.20(\mathrm{~d}, \mathrm{~J}=9.5 \mathrm{~Hz}, 1 \mathrm{H}), 7.71(\mathrm{~d}, \mathrm{~J}=7.5 \mathrm{~Hz}, 1 \mathrm{H}), 7.26$ $(\mathrm{d}, \mathrm{J}=9.5 \mathrm{~Hz}, 1 \mathrm{H}), 7.08-7.04(\mathrm{~m}, 2 \mathrm{H}), 6.94(\mathrm{~d}, \mathrm{~J}=9.5 \mathrm{~Hz}, 1 \mathrm{H}), 6.88(\mathrm{~d}, \mathrm{~J}=9.0 \mathrm{~Hz}, 1 \mathrm{H}), 6.63-$ 6.59 (m, 2H). ${ }^{13} \mathrm{C}$ NMR (100 MHz, $\left.\mathrm{CDCl}_{3}, \delta\right): 155.45,152.66,144.26,143.79,137.69,135.28$, $131.39,128.03,127.16,126.10,121.46,121.33,119.99,117.44,117.19,111.91,111.27,108.71$ 108.56, 108.43, 83.51, 24.98. ESI-HRMS (m/z): calculated for $\mathrm{C}_{26} \mathrm{H}_{21} \mathrm{BO}_{4}\left[\mathrm{M}^{+}\right]$: 408.1533; found: 408.1544 .

Compound 6. A flame dried, $50 \mathrm{ml}$ round-bottom flask equipped with a magnetic stir bar was charged with $100 \mathrm{mg}$ of 5 ( $245 \mu \mathrm{mol}), 84 \mathrm{mg}$ of 4-bromo-2,5-di-t-butylaniline ( $294 \mu \mathrm{mol}, 1.2$ equiv.), $101 \mathrm{mg}$ of potassium carbonate (745 $\mu \mathrm{mol}, 3$ equiv) and $28 \mathrm{mg}$ of $\mathrm{Pd}\left(\mathrm{PPh}_{3}\right)_{4}(25 \mu \mathrm{mol}$, 0.1 equiv.). After three pump-purge cycles, a solvent mixture of toluene/ethanol/water (2/1/1) purged with $\mathrm{N}_{2}$ for 15 min was added to the reaction vessel and the mixture was heated at reflux for $16 \mathrm{~h}$. After the reaction was cooled down, the mixture was diluted with $100 \mathrm{ml}$ of $\mathrm{CH}_{2} \mathrm{Cl}_{2}$ and washed with $15 \mathrm{ml}$ of water three times. The solvent in the organic layer was removed on a rotary evaporator. The crude product was then purified by silica gel column chromatography with $16 \%$ $\mathrm{CH}_{2} \mathrm{Cl}_{2}$ in hexane then $40 \% \mathrm{CH}_{2} \mathrm{Cl}_{2}$ in hexane as eluents to yield $89 \mathrm{mg}$ ( $73 \%$ ) of orange solid as the product. ${ }^{1} \mathrm{H}$ NMR $\left(500 \mathrm{MHz}, \mathrm{CDCl}_{3}\right), \delta: 7.32(\mathrm{~d}, \mathrm{~J}=9.0 \mathrm{~Hz}, 1 \mathrm{H}), 7.12-7.06(\mathrm{~m}, 2 \mathrm{H}), 7.00(\mathrm{~d}$, $\mathrm{J}=7.8 \mathrm{~Hz}, 1 \mathrm{H}), 6.95(\mathrm{~d}, \mathrm{~J}=9.0 \mathrm{~Hz}, 1 \mathrm{H}), 6.88(\mathrm{~d}, \mathrm{~J}=9.3 \mathrm{~Hz}, 1 \mathrm{H}), 6.84-6.76(\mathrm{~m}, 2 \mathrm{H}), 6.68(\mathrm{~d}, \mathrm{~J}=$ $7.8 \mathrm{~Hz}, 1 \mathrm{H}), 6.66-6.60(\mathrm{~m}, 1 \mathrm{H}), 3.86(\mathrm{br}, 2 \mathrm{H}), 1.38(\mathrm{~s}, 9 \mathrm{H}), 1.11(\mathrm{~s}, 9 \mathrm{H})$. 


\section{Steady-State Optical Spectroscopy}

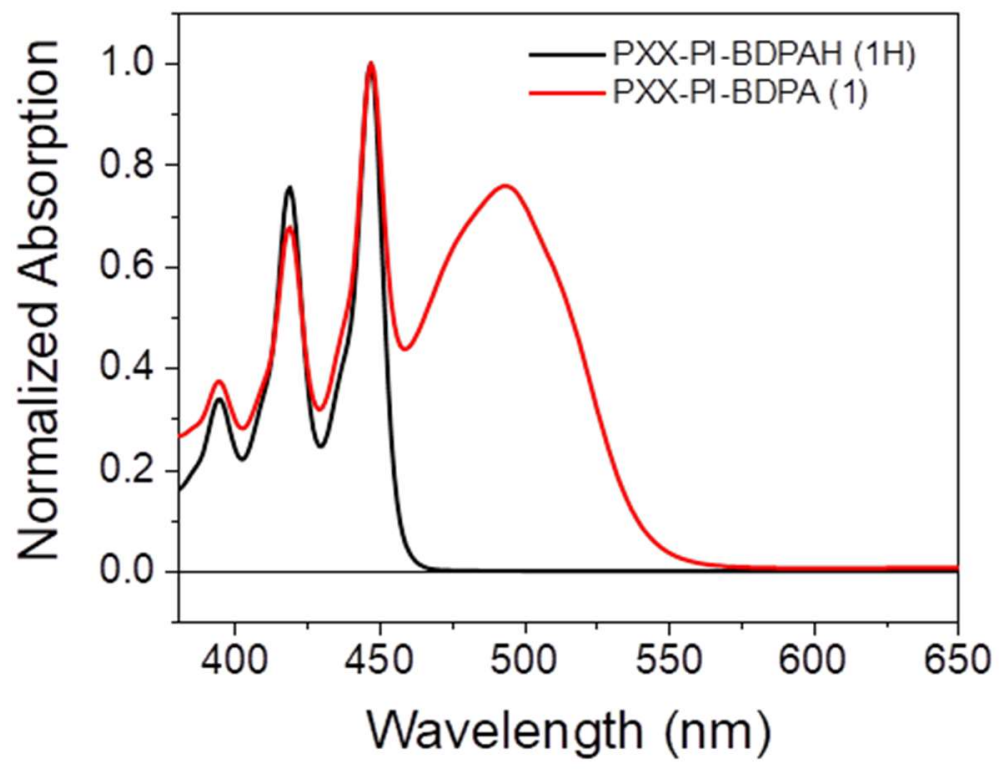

Figure S1. UV-Vis absorption spectra recorder using a Shimadzu 1800 spectrophotometer. Spectra of $\mathbf{1}$ and its non-radical precursor $\mathbf{1 H}$ in toluene at $295 \mathrm{~K}$. 


\section{Electrochemistry and Energetics}

Measurements were performed on a CH Instruments Model 660A electrochemical workstation.

Samples were measured in a solution of $0.1 \mathrm{M}$ tetrabutylammonium hexafluorophosphate (TBAPF 6 ) in $\mathrm{CH}_{2} \mathrm{Cl}_{2}$ purged with $\mathrm{Ar}$ to remove oxygen. A $1.0 \mathrm{~mm}$ diameter platinum disk electrode, platinum wire counter electrode, and saturated calomel electrode (SCE) reference electrode were used.

a)

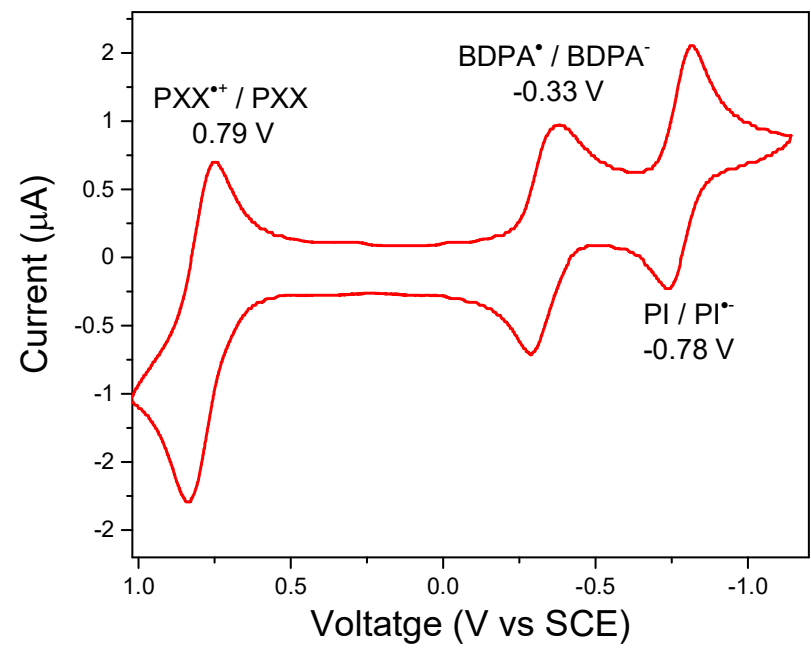

b)

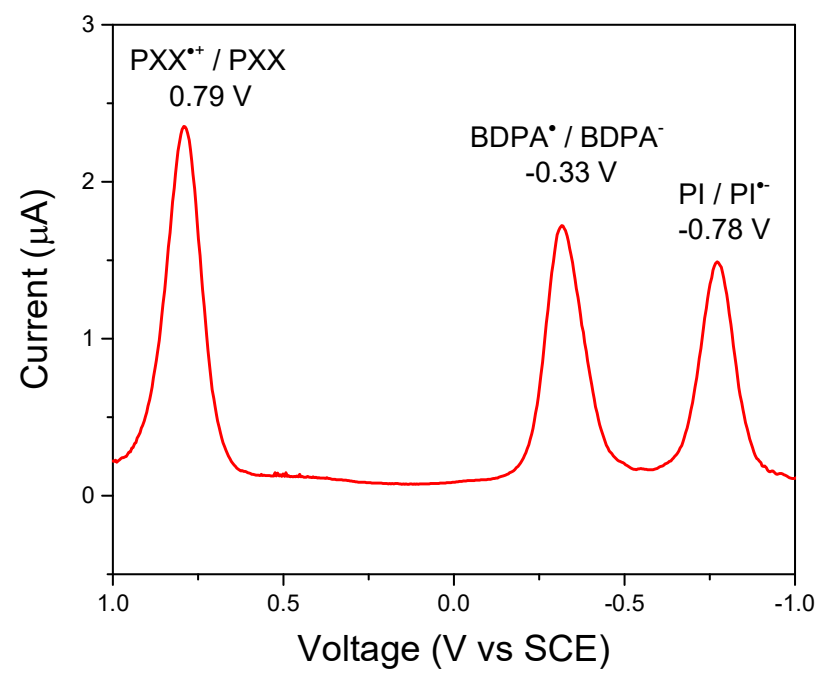

Figure S2. Cyclic (a) and differential-pulse (b) voltammetry of $\mathbf{1}$ in $\mathrm{CH}_{3} \mathrm{CN}(0.1 \mathrm{M}$ tetrabutylammonium hexafluorophosphate). Results are reported vs. SCE. 
The structure of 1 was optimized using molecular mechanics with the MMFF94 force field in Avogadro 1.1.1. ${ }^{3}$ The ion pair distances $\left(\mathrm{r}_{\mathrm{DA}}\right)$ were estimated using the distance between the centers of PXX and PI (12.9 $\AA)$, and PXX and BDPA (21.9 $\AA)$. The free energies of reaction for the charge transfer reactions in different solvent environments can be estimated using Weller equation,(ref) which calculates the Gibbs free energy change for ion pair (IP) states with the solvent correction accounting for different solvent environments.

$$
\begin{aligned}
& \Delta G_{I P}=\left[E^{r e d}\left(D^{+} / D\right)-E^{r e d}\left(A / A^{-}\right)\right]+\Delta G_{\text {Sol }} \\
& \Delta G_{\text {Sol }}=-\frac{e^{2}}{4 \pi \varepsilon_{0}}\left[\frac{1}{\varepsilon_{S}} \cdot \frac{1}{R_{D A}}+\left(\frac{1}{\varepsilon_{r e f}}-\frac{1}{\varepsilon_{S}}\right)\left(\frac{1}{2 r_{A^{-}}}+\frac{1}{2 r_{D^{+}}}\right)\right]
\end{aligned}
$$

In eq $2, \varepsilon_{0}$ is the vacuum permittivity, $\varepsilon_{s}$ and $\varepsilon_{r e f}$ is the dielectric constants of the solvents in which the charge transfer reactions occur and in which the redox potentials are measured respectively, $R_{D A}$ is the electron donor-acceptor distance extracted from molecular modeling, and $r_{D+}$ and $r_{A-}$ are the ionic radii of the electron donor cation and acceptor anion, respectively. The ionic radii are estimated from the size of the relevant $\pi$ systems of $\mathrm{PXX}^{{ }^{+}}\left(r_{D^{+}}=4.4 \AA\right), \mathrm{PI}^{\bullet^{-}}\left(r_{A^{-}}=\right.$ $3.7 \AA)$, and $\operatorname{BDPA}^{-}\left(r_{A_{-}}=4.4 \AA\right)$. The calculated values are listed in Table S1.

\begin{tabular}{|c|c|c|}
\hline Reaction & $\begin{array}{c}\Delta G(e V) \\
\left(\varepsilon_{s}=2.3\right)\end{array}$ & $\begin{array}{l}\Delta G(\mathrm{eV}) \\
\left(\varepsilon_{\mathrm{s}}=3.4\right)\end{array}$ \\
\hline 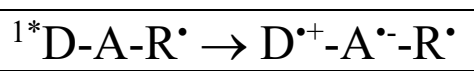 & -0.47 & -0.82 \\
\hline $\mathrm{D}^{\cdot+}-\mathrm{A}^{\bullet-}-\mathrm{R}^{\bullet} \rightarrow \mathrm{D}^{\bullet+}-\mathrm{A}-\mathrm{R}^{-}$ & -0.25 & -0.37 \\
\hline $\mathrm{D}^{\bullet+}-\mathrm{A}-\mathrm{R}^{-} \rightarrow{ }^{3 *} \mathrm{D}-\mathrm{A}-\mathrm{R}^{\bullet}$ & -0.10 & 0.37 \\
\hline $\mathrm{D}^{\cdot+}-\mathrm{A}-\mathrm{R}^{-} \rightarrow \mathrm{D}-\mathrm{A}-\mathrm{R}^{\bullet}$ & -2.00 & -1.53 \\
\hline $\mathrm{D}^{\bullet+}-\mathrm{A}^{\bullet-}-\mathrm{R}^{\bullet} \rightarrow \mathrm{D}-\mathrm{A}-\mathrm{R}^{\bullet}$ & -2.25 & -1.90 \\
\hline
\end{tabular}

Table S1. Free energies of reaction for various charge transfer reactions in different solvents. 


\section{Transient absorption spectroscopy and kinetics}

Femtosecond visible transient absorption (fsTA) spectroscopy experiments were conducted using a commercial regeneratively amplified Ti:sapphire laser system (Tsunami oscillator/Spitfire amplifier, Spectra-Physics, lab-built optical parametric amplifier ${ }^{4}$ ) described previously ${ }^{5}$. Before interaction with the sample, the probe was split using a neutral density filter so that one portion interacted with the sample and one portion provided a reference spectrum. The pump (550 or 510 $\mathrm{nm}, 1 \mu \mathrm{J} /$ pulse, $120 \mathrm{fs}$ ) was sent through a commercial depolarizer (DPU-25-A, Thorlabs, Inc.) to suppress the effects of rotational dynamics and chopped at $500 \mathrm{~Hz}$. The pump was focused to about $0.2 \mathrm{~mm}$ diameter and the probe to about $0.1 \mathrm{~mm}$ diameter at the sample. The reference probe and the transmitted probe were coupled into optical fibers and detected using a customized Helios spectrometer and Helios software (Ultrafast Systems, LLC). Nanosecond visible transient absorption (nsTA) spectroscopy experiments were performed using the pump pulse described for the fsTA experiments paired with a photonic crystal fiber ultra-broadband probe generated by a customized EOS spectrometer (Ultrafast Systems, LLC). The temporal resolution was about 120 $280 \mathrm{fs}$ in the fsTA experiments and about $600-900 \mathrm{ps}$ in the nsTA experiments. Visible fsTA spectra were collected for $3 \mathrm{~s}$ at each pump-probe time delay; nsTA spectra were collected using similar durations. Samples for room-temperature TA was dissolved in toluene and prepared with an optical density of 0.8 at $450 \mathrm{~nm}$ in $2 \mathrm{~mm}$ quartz cuvettes fused to a glass bulb. This bulb was used to subject each sample to four freeze-pump-thaw cycles under vacuum (10-4 Torr) to remove oxygen. Samples were stirred to minimize the effects of local heating and degradation. Samples for low-temperature TA were dissolved in $\mathrm{CH}_{2} \mathrm{Cl}_{2}$ and prepared with an optical density of 0.8 at $450 \mathrm{~nm}$ in a $2 \mathrm{~mm}$ quartz cuvette. The solution was then evaporated to dryness with a stream of $\mathrm{N}_{2}$ in a small vial and was placed in a $\mathrm{N}_{2}$-atmosphere glovebox. Inside the glovebox, a volume of 
$\operatorname{PrCN}$ or $\operatorname{PrCN} / \mathrm{EtCN}, 9 / 2$, v/v mixture equivalent to the amount of $\mathrm{CH}_{2} \mathrm{Cl}_{2}$ used previously was added to the vial to obtain a solution of similar optical density. This solution was then sealed in a sample cell consisting of two quartz windows separated by a $2 \mathrm{~mm}$ PTFE spacer. The sealed sample cell was then removed from the glovebox and placed inside a Janis VNF-100 cryostat (Janis Research Co. LLC) coupled to a Cryo-Con 32B (cryogenics Control Systems, Inc.) temperature controller. The sample was then cooled to $105 \mathrm{~K}$ or $140 \mathrm{~K}$ with liquid $\mathrm{N}_{2}$ to measure the TA spectra.

All datasets were background subtracted to remove scattered pump light and spontaneous emission and corrected for group delay dispersion and time zero using Surface Xplorer (Ultrafast Systems, LLC). Data for fsTA of 1 were globally fitted to the following model that accounts for the spin selectivity, where $A_{S}$ and $A_{T}$ are ${ }^{1^{*}} \mathrm{D}-\mathrm{A}-\mathrm{R}^{*}, B_{S}$ and $B_{T}$ are $\mathrm{D}^{{ }^{+}-}{ }_{-}\left(\mathrm{A}^{*--}-\mathrm{R}^{*}\right)$ and $\mathrm{D}^{{ }^{+}-}{ }_{-}\left(\mathrm{A}^{-*}-\mathrm{R}^{*}\right)$ respectively, $C_{S}$ is $\mathrm{D}^{-+}-\mathrm{A}-\mathrm{R}^{-}$and $C_{T}$ is an empty component to balance the matrix dimension. Since spin statistics is assumed, the initial condition of $\left[A_{T}\right]:\left[A_{S}\right]=3: 1$ is used for the fitting.

$$
\frac{d}{d t}\left[\left(\begin{array}{l}
{\left[A_{T}\right]} \\
{\left[B_{T}\right]} \\
{\left[C_{T}\right]}
\end{array}\right)+\left(\begin{array}{l}
{\left[A_{S}\right]} \\
{\left[B_{S}\right]} \\
{\left[C_{S}\right]}
\end{array}\right]\right)=\left(\begin{array}{ccc}
-k_{C S 1}^{T} & 0 & 0 \\
k_{C S}^{T} & -k_{C R}^{T} & 0 \\
0 & 0 & 0
\end{array}\right)\left(\begin{array}{l}
{\left[A_{T}\right]} \\
{\left[B_{T}\right]} \\
{\left[C_{T}\right]}
\end{array}\right)+\left(\begin{array}{ccc}
-k_{C S 1}^{S} & 0 & 0 \\
k_{C S 1}^{S} & -k_{C S 2}^{S} & 0 \\
0 & k_{C S 2}^{S} & -k_{C R}^{S}
\end{array}\right)\left(\begin{array}{l}
{\left[A_{S}\right]} \\
{\left[B_{S}\right]} \\
{\left[C_{S}\right]}
\end{array}\right)
$$

Data for nsTA of $\mathbf{1}$ were globally fitted to the following models as listed in Table S2:

Table S2. Kinetic matrices

\begin{tabular}{|c|c|}
\hline Temperature (K) & Kinetic Matrix \\
\hline 295 & $\left(-k_{\mathrm{CR} 2}\right)$ \\
\hline \multirow{2}{*}{140} & $\left(\begin{array}{cc}-k_{C R}^{T} & 0 \\
0 & -k_{C R 2}^{S}\end{array}\right)$ \\
\hline \multirow{2}{*}{105} & $\left(\begin{array}{ccc}-k_{C R}^{T} & 0 & 0 \\
0 & -k_{C R 2}^{S} & 0 \\
0 & 0 & -k_{T}\end{array}\right)$ \\
\hline
\end{tabular}



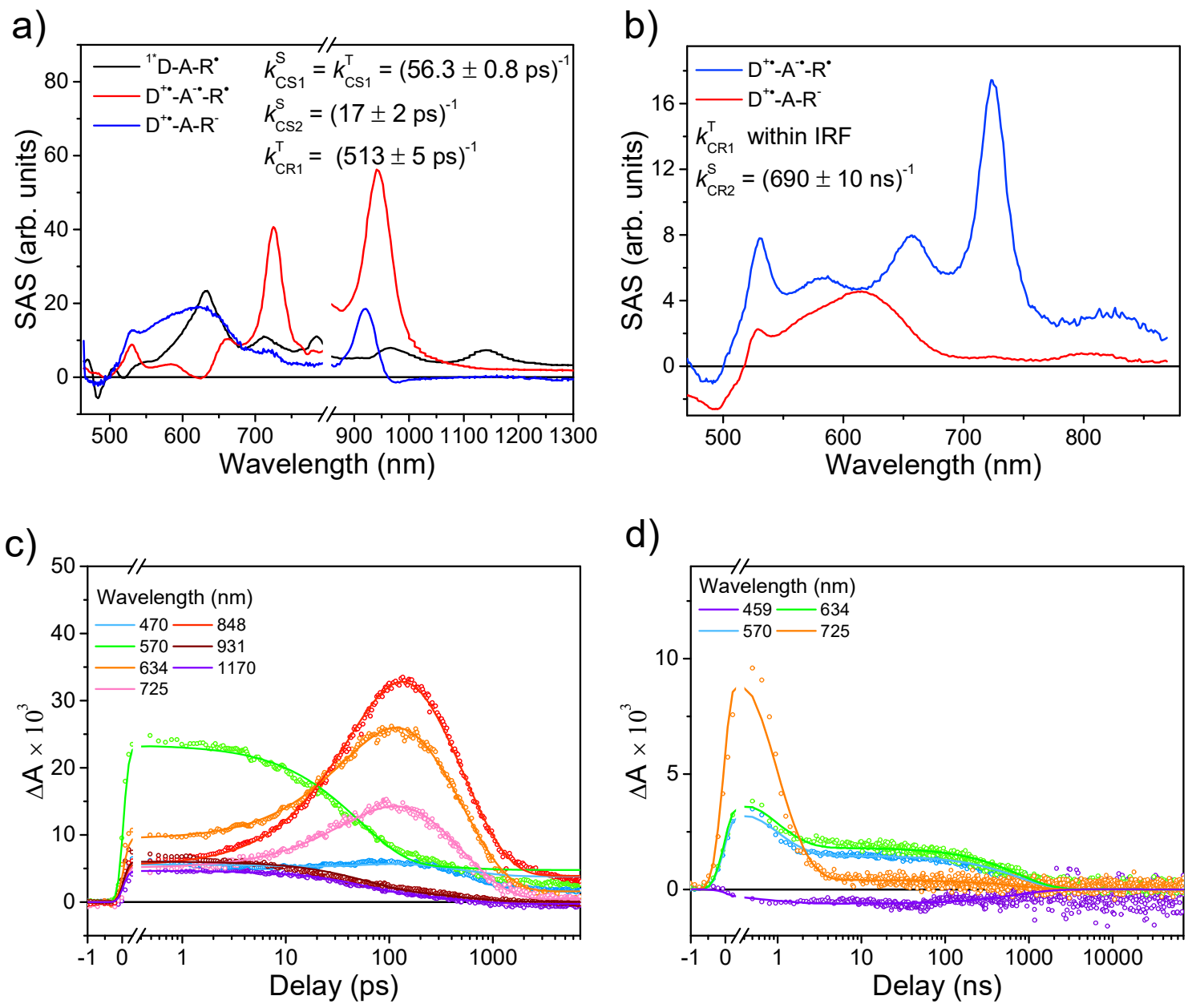

Figure S3. FsTA (a) and nsTA (b) species-associated spectra of 1 in a $9 / 2 \mathrm{PrCN} / \mathrm{EtCN}$ at $140 \mathrm{~K}$ following $\lambda_{\mathrm{ex}}=450 \mathrm{~nm}$ excitation. c) and d) Kinetic traces and their fits at selected probe wavelengths for the fsTA and nsTA data, respectively. 

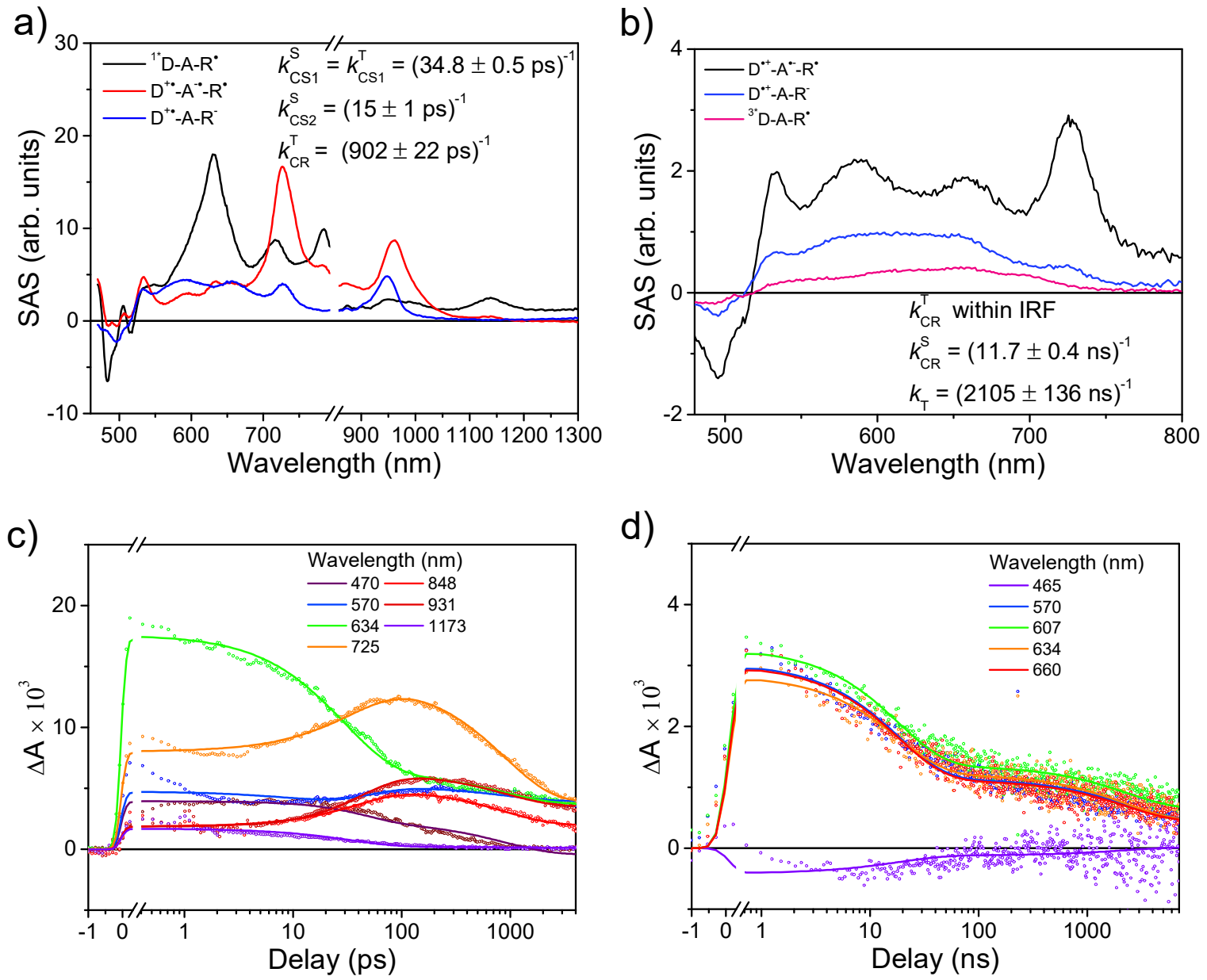

Figure S4. FsTA (a) and nsTA (b) species-associated spectra of 1 in a $\operatorname{PrCN}$ at $105 \mathrm{~K}$ following $\lambda_{\mathrm{ex}}=$ $450 \mathrm{~nm}$ excitation resulting from the global fitting of the data to an $\mathrm{A} \rightarrow \mathrm{B} \rightarrow \mathrm{C} \rightarrow \mathrm{GS}$ model that includes spin-selectivity. c) and d) Kinetic traces and their fits at selected probe wavelengths for the fsTA and nsTA data, respectively. 
a)

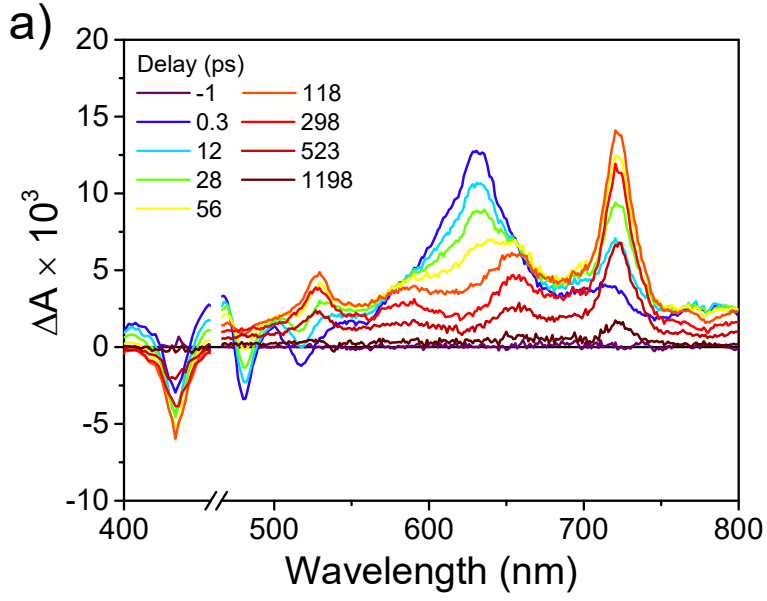

C)

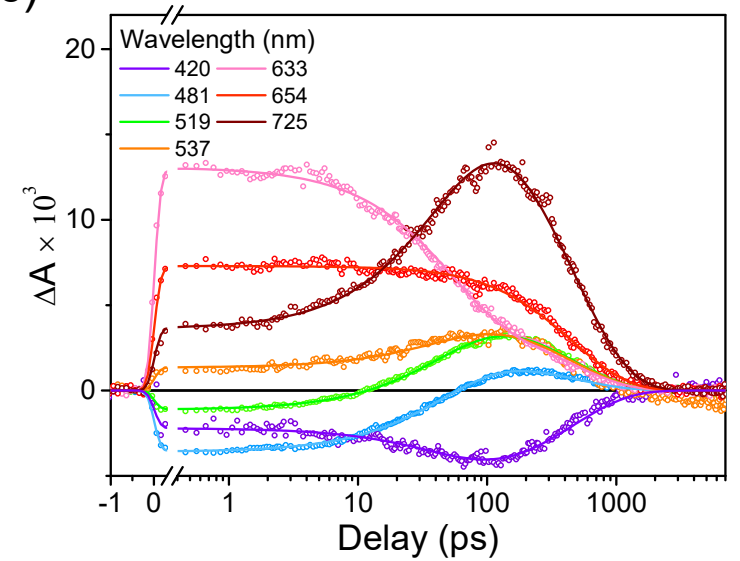

b)

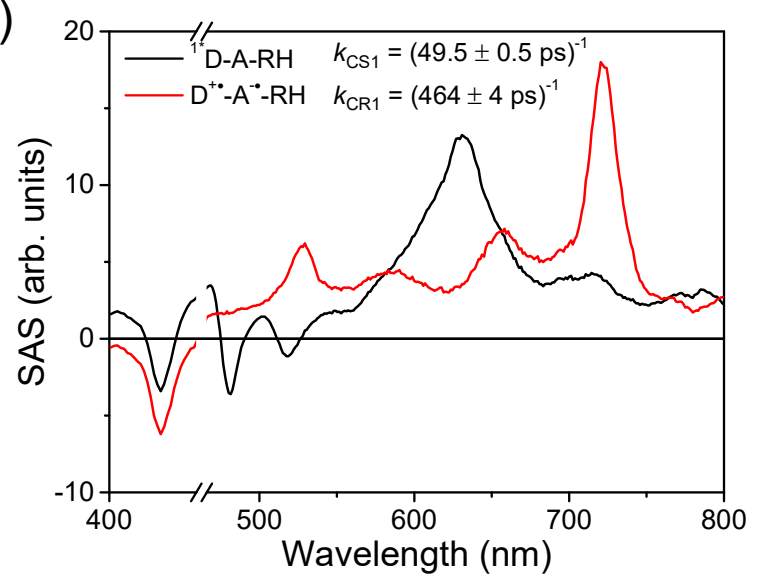

Figure S5. Transient absorption spectra of 1H. a) fsTA data of $\mathbf{1 H}$ at 140K in PrCN/EtCN 9:2 solution. b) species-associated spectrum resulting from the global fitting of the data to an $\mathrm{A} \rightarrow \mathrm{B} \rightarrow \mathrm{GS}$ model. c) Kinetic traces and their fits at selected probe wavelengths 
a)
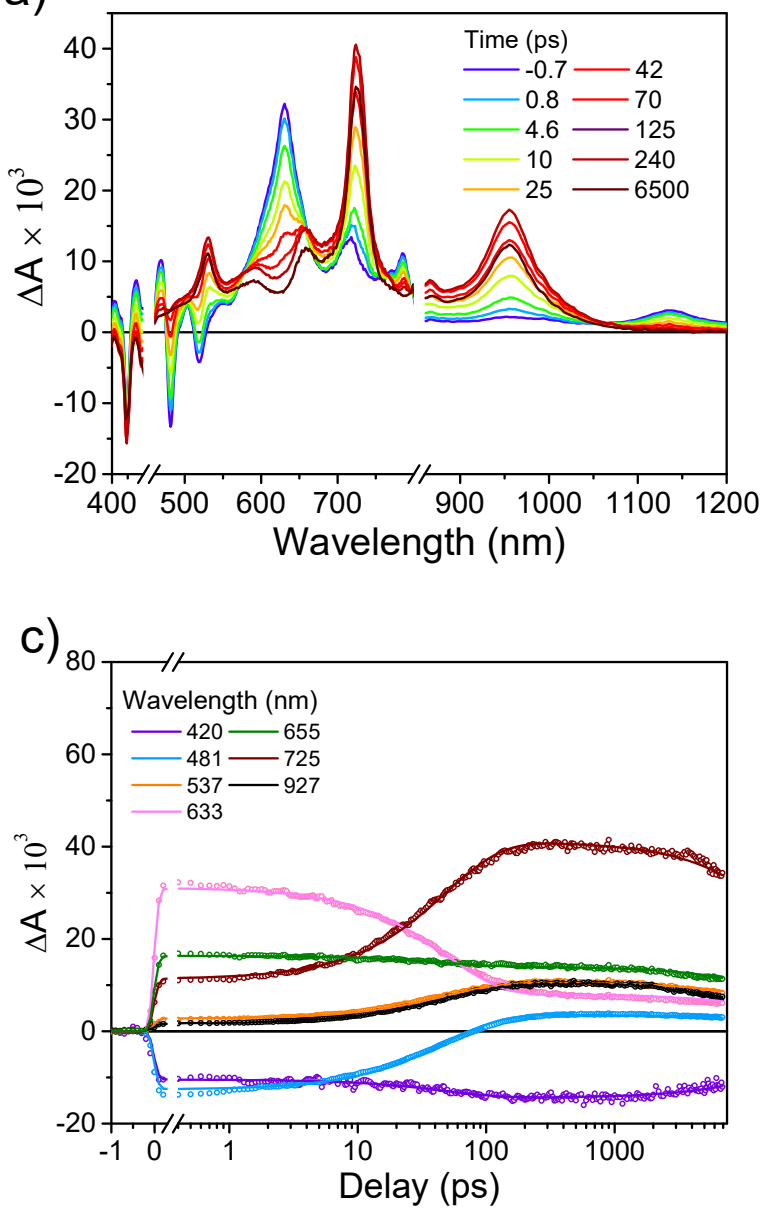

b)

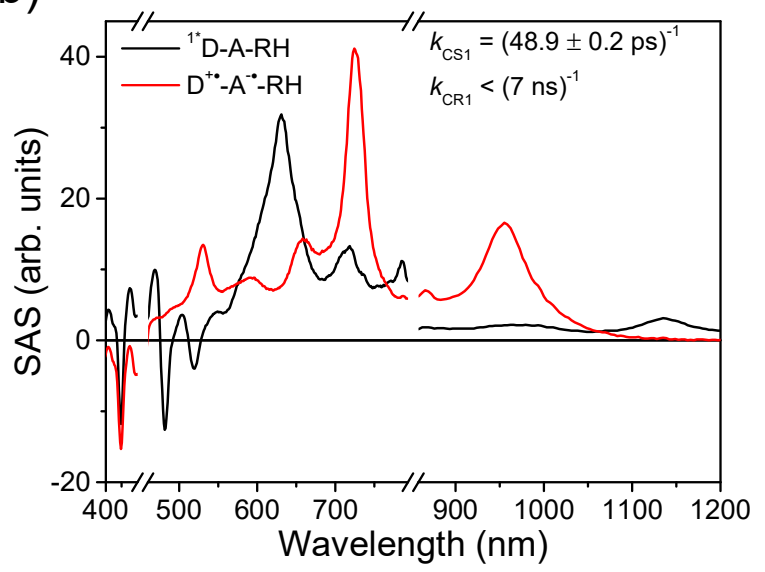

Figure S6. a) fsTA data of $\mathbf{1 H}$ at $105 \mathrm{~K}$ in PrCN. c) species-associated spectrum resulting from the global fitting of the data to an $\mathrm{A} \rightarrow \mathrm{B} \rightarrow$ GS model. c) Kinetic traces and their fits at selected probe wavelengths. 

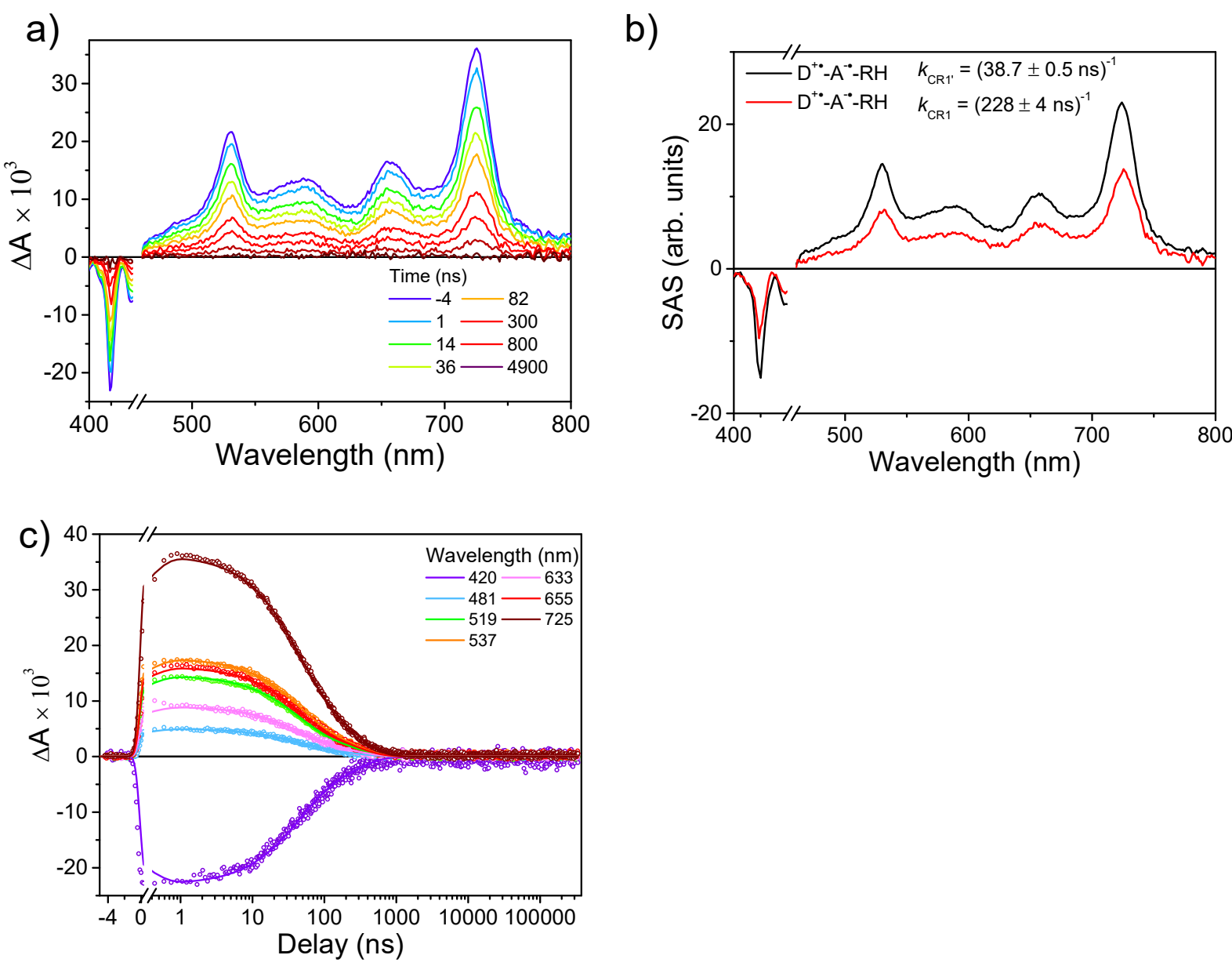

Figure S7. a) NsTA data of $\mathbf{1 H}$ at $105 \mathrm{~K}$ in PrCN. b) Decay-associated spectrum resulting from the global fitting of the data to two exponential decays. c) Kinetic traces and their fits at selected probe wavelengths. 
a)
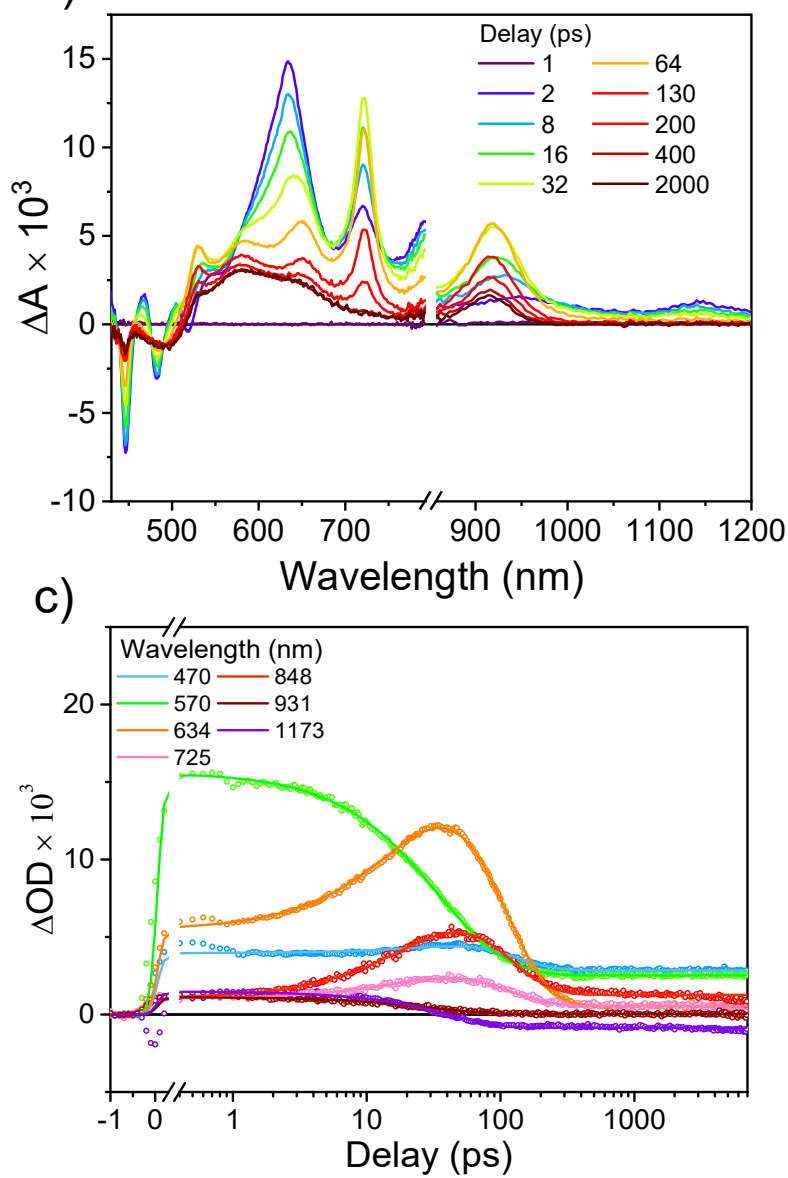

b)

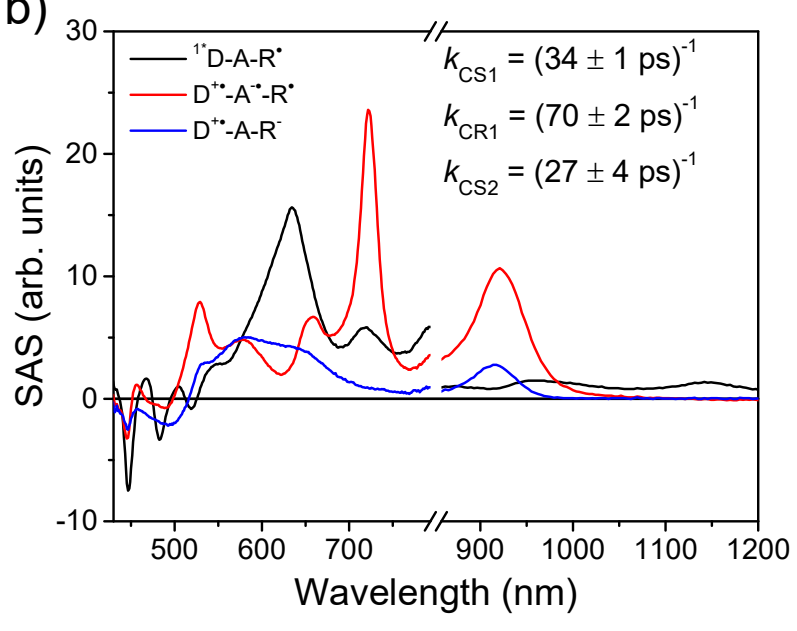

Figure S8. (a) FsTA spectra of 1 in toluene at $295 \mathrm{~K}$ following $\lambda_{\mathrm{ex}}=450 \mathrm{~nm}$ excitation. (b) Speciesassociated spectra for the data in (a) resulting from the global fitting of the data to a model that includes spin-selectivity and an $\mathrm{A} \rightarrow \mathrm{B} \rightarrow \mathrm{G}$ model. (c) Kinetic traces and their fits at selected probe wavelengths. 
a)
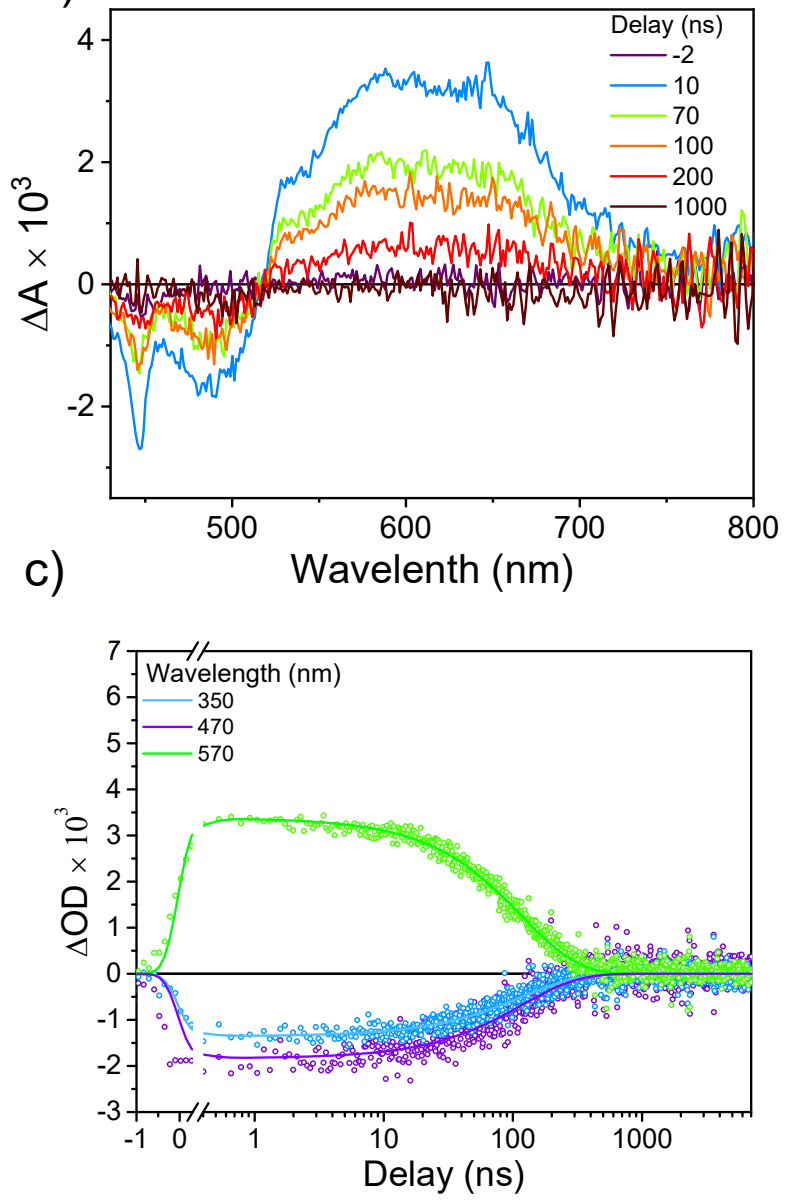

b)

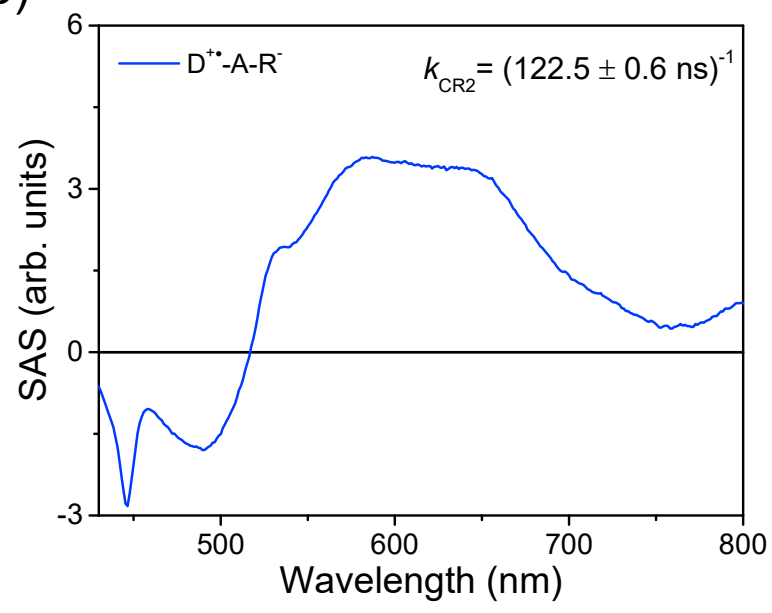

Figure S9. (a) NsTA spectra of 1 in toluene at $295 \mathrm{~K}$ following $\lambda_{\mathrm{ex}}=450 \mathrm{~nm}$ excitation. (b) Speciesassociated spectra for the data in (a) resulting from the global fitting of the data to a model that includes spin-selectivity and an $\mathrm{A} \rightarrow \mathrm{G}$ model. (c) Kinetic traces and their fits at selected probe wavelengths. 

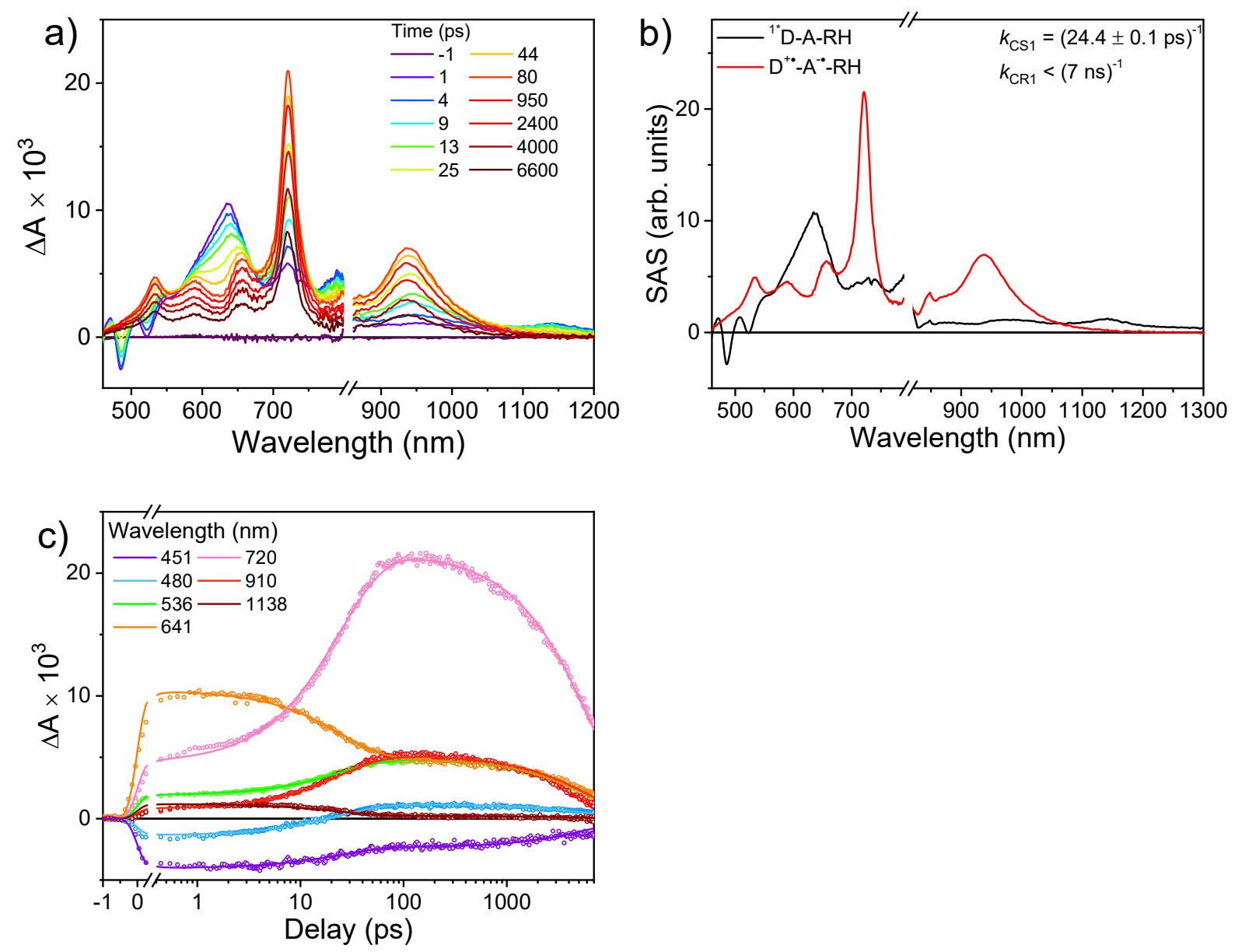

Figure S10. (a) FsTA spectra of $1 \mathbf{H}$ in toluene at $295 \mathrm{~K}$ following $\lambda_{\mathrm{ex}}=450 \mathrm{~nm}$ excitation. (b) Speciesassociated spectra for the data in (a) resulting from the global fitting of the data to an $A \rightarrow B \rightarrow G$ model. (c) Kinetic traces and their fits at selected wavelengths. 

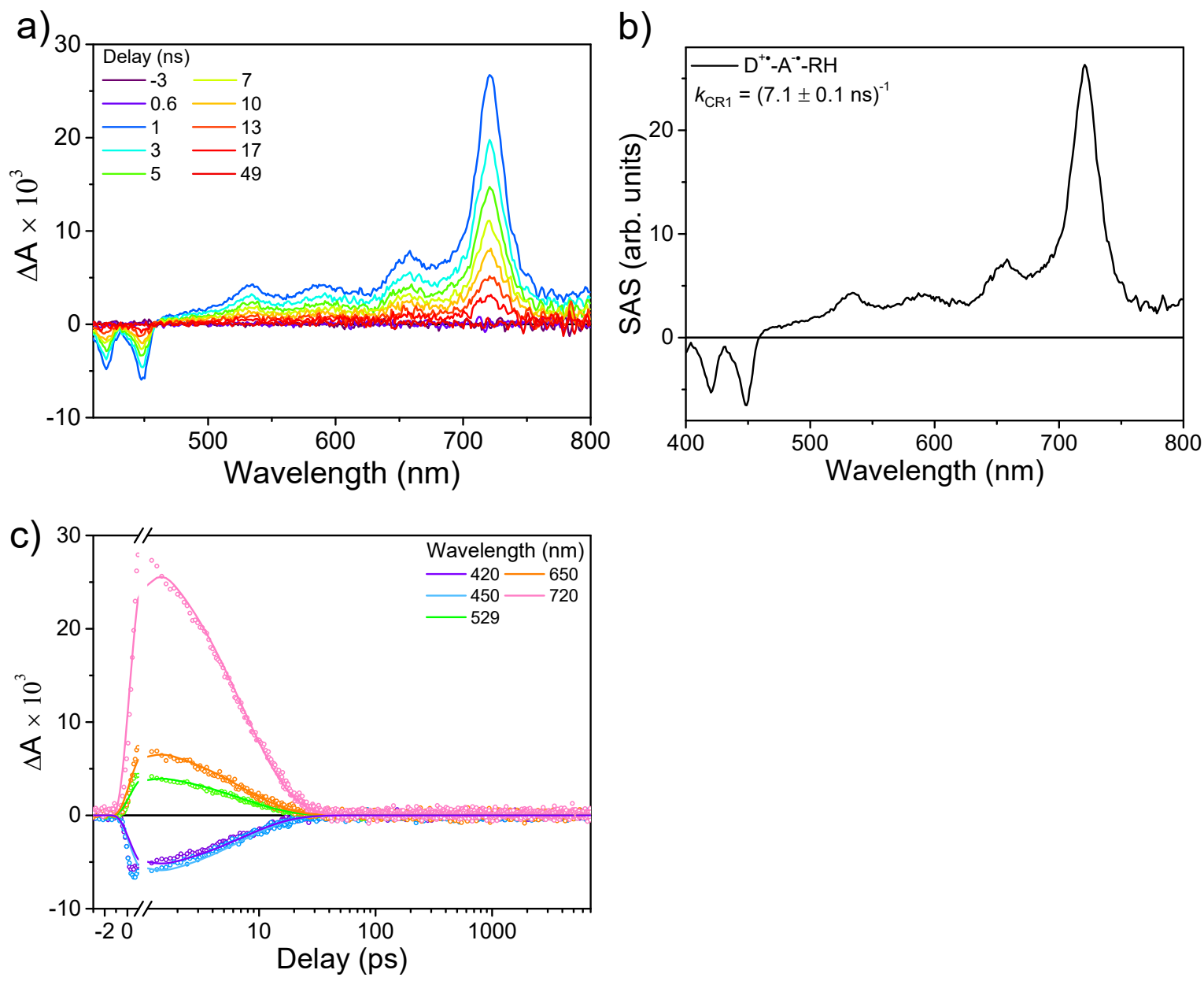

Figure S11. (a) NsTA spectra of $1 \mathbf{H}$ in toluene at $295 \mathrm{~K}$ following $\lambda_{\mathrm{ex}}=450 \mathrm{~nm}$ excitation. (b) Speciesassociated spectra for the data in (a) resulting from the global fitting of the data to an $A \rightarrow G$ model. (c) Kinetic traces and their fits at selected wavelengths. 


\section{EPR spectroscopy}

Measurements were made at X-band $(\sim 9.6 \mathrm{GHz})$ on a Bruker Elexsys E680 X/W EPR spectrometer with a split ring resonator (ER4118X-MS3). The temperature was set by an Oxford Instruments CF935 continuous flow optical cryostat with liquid nitrogen. Solutions $(\sim 30 \mu \mathrm{L})$ were loaded into quartz tubes $(2.40 \mathrm{~mm}$ o.d., 2.00 i.d.), subjected to three freeze-pump-thaw cycles on a vacuum line $\left(10^{-4}\right.$ Torr $)$, and sealed with a hydrogen torch. The samples were pre-frozen before inserting into the pre-cooled instrument. Light from the pulsed laser was coupled through a fiber placed outside the cryostat window $(\sim 2 \mathrm{~mJ} /$ pulse $)$, with some portion of the light passing through the coils of the resonator and exciting the sample.

Measurements using continuous wave $(\mathrm{CW})$ microwaves and direct detection were performed. Following photoexcitation, kinetic traces of transient magnetization under $\mathrm{CW}$ microwave irradiation were obtained in both imaginary and real channels (quadrature detection). Time traces were recorded over a range of magnetic fields to give 2D spectra. Spectra were processed by first subtracting the signal prior to the laser pulse for each kinetic trace (at a given magnetic field point), and then subtracting the signal average at off-resonance magnetic field points from the spectra obtained at a given time.

The TREPR spectra of PXX and 1 were fit using pepper function in EasySpin ${ }^{6}$. The model to which the spectrum of $\mathbf{1}$ was fit has been described in the main text. The fit parameters for both spectra are given in Table S3 and Table S4. 


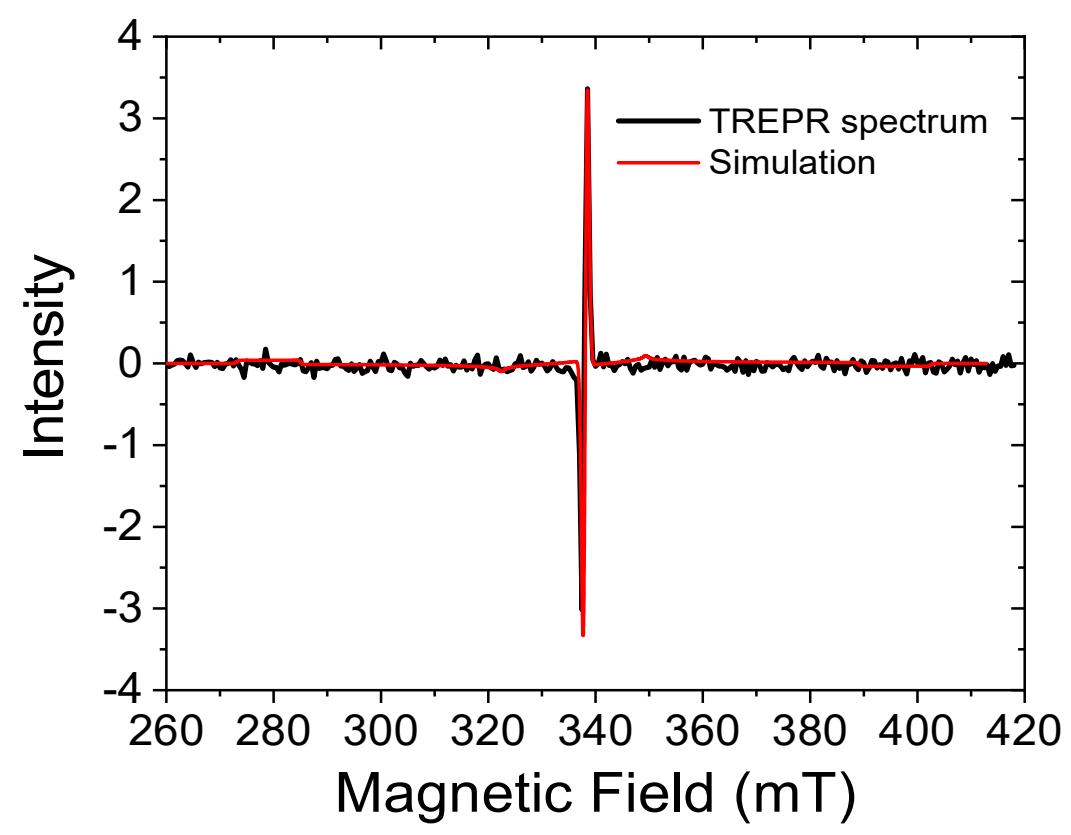

Figure S12. TREPR spectrum of 1 at X-band in PrCN at $105 \mathrm{~K}, 100 \mathrm{~ns}$ after a $7 \mathrm{~ns}, 450 \mathrm{~nm}$ laser pulse. Simulation is shown in red.

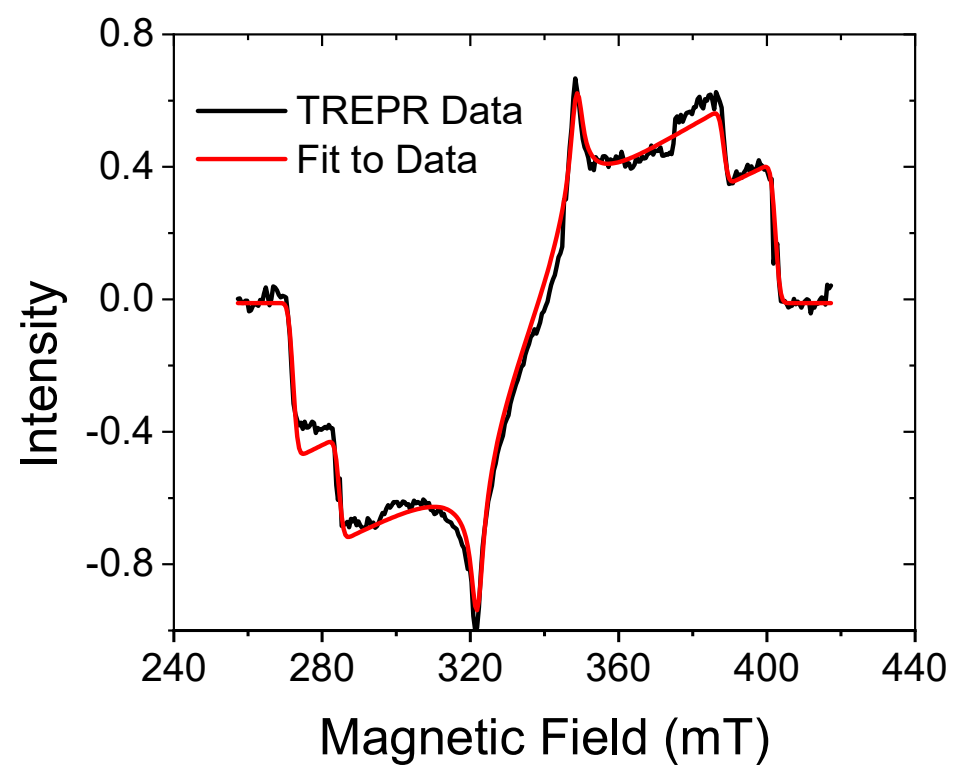

Figure S13. TREPR spectra obtained using direct detection at $85 \mathrm{~K}$ in mTHF for PXX $(\sim 100 \mu \mathrm{M})$ after a $7 \mathrm{~ns}$ laser pulse, with the fit to a standard spin-orbit intersystem crossing model shown in red. 
Table S3. Triplet fit parameters

\begin{tabular}{|c|c|c|}
\hline $\begin{array}{c}\text { Zero-Field Splitting } \\
\text { (MHz) }\end{array}$ & Population & $\begin{array}{c}\text { Peak-Peak } \\
\text { Linewidth (mT) }\end{array}$ \\
\hline$|\mathrm{D}|=1824$ & $\mathrm{~T}_{\mathrm{x}}=1$ & \\
$|\mathrm{E} / \mathrm{D}|=0.197$ & $\mathrm{~T}_{\mathrm{y}}=1$ & 1.63 \\
$\mathrm{~T}_{\mathrm{z}}=0$ & \\
\hline
\end{tabular}

Table S4. Coupled triplet-doublet pair fit parameters

\begin{tabular}{|c|c|c|c|c|}
\hline $\begin{array}{c}\text { Exchange } \\
\text { coupling } \\
J_{T R}(\mathrm{MHz})\end{array}$ & $\begin{array}{c}\text { Zero-Field } \\
\text { Splitting } D_{T} \\
\quad(\mathrm{MHz})\end{array}$ & $\begin{array}{c}\text { Dipolar } \\
\text { coupling } \\
D_{T R} \\
(\mathrm{MHz})\end{array}$ & Population & $\begin{array}{c}\text { Peak- } \\
\text { Peak } \\
\text { Linewidth } \\
(\mathrm{mT})\end{array}$ \\
\hline-12 & $\begin{aligned}|\mathrm{D}| & =1824 \\
\mathrm{E} / \mathrm{D} & =-0.197\end{aligned}$ & 5 & $\begin{array}{l}\left|Q_{3 / 2}\right\rangle=0 \\
\left|Q_{1 / 2}\right\rangle=0.25 \\
\left|D_{1 / 2}\right\rangle=0.25 \\
\left|D_{-/ 2}\right\rangle=0.25 \\
\left|Q_{-1 / 2}\right\rangle=0.25 \\
\left|Q_{-3 / 2}\right\rangle=0\end{array}$ & 0.6 \\
\hline
\end{tabular}

\section{References}

1. Rugg, B. K.; Phelan, B. T.; Horwitz, N. E.; Young, R. M.; Krzyaniak, M. D.; Ratner, M. A.; Wasielewski, M. R., Spin-selective photoreduction of a stable radical within a covalent donoracceptor-radical triad. J. Am. Chem. Soc. 2017, 139, 15660-15663.

2. Kamei, T.; Uryu, M.; Shimada, T., Cu-catalyzed aerobic oxidative C-H/C-O cyclization of 2,2'-binaphthols: Practical synthesis of PXX derivatives. Org. Lett. 2017, 19, 2714-2717.

3. Hanwell, M. D.; Curtis, D. E.; Lonie, D. C.; Vandermeersch, T.; Zurek, E.; Hutchison, G. R., Avogadro: An advanced semantic chemical editor, visualization, and analysis platform. $J$. Cheminform. 2012, 4, 17.

4. Greenfield, S. R.; Wasielewski, M. R., Near-transform-limited visible and near-IR fs pulses from an OPA using type II $\beta$-barium borate. Opt. Lett. 1995, 20, 1394-1396.

5. Young, R. M.; Dyar, S. M.; Barnes, J. C.; Juricek, M.; Stoddart, J. F.; Co, D. T.; Wasielewski, M. R., Ultrafast conformational dynamics of electron transfer in exbox ${ }^{4+} \subset$ tperylene. J. Phys. Chem. A 2013, 117, 12438-12448.

6. Stoll, S.; Schweiger, A., Easyspin, a comprehensive software package for spectral simulation and analysis in EPR. J. Magn. Reson. 2006, 178, $42-55$. 